\title{
Intercultural Communicative Competence, Self-Esteem Cultural Competence of Nursing Students
}

\author{
Minsun Song ${ }^{1}$ and Namyoung Yang ${ }^{2}$ \\ Dept. of Nursing Science, Konyang University \\ 158 KwanJeoDong-ro, Seo-gu, Daejeon, 302-718, Korea \\ ${ }^{1}$ mssong@konyang.ac.kr, ${ }^{2}$ Corresponding Author: nyyang@konyang.ac.kr
}

\begin{abstract}
This study was examined closely on intercultural communicative competence, self-esteem, and cultural competence of nursing students. The subjects consisted of 158 students. The data were collected at September 2016 and analyzed using descriptive statistics, Pearson correlation coefficients, and stepwise multiple regression. The mean scores of intercultural communicative competence, self-esteem, and cultural competence were above the average. Significant correlations were found between intercultural communicative competence and cultural competence, self-esteem and cultural competence. Cultural competence was a predictor of intercultural communicative competence and self-esteem. These findings indicate that perceived intercultural communicative competence and self-esteem may be necessary to improve cultural competence among nursing students.
\end{abstract}

Keywords: Intercultural, Communicative, Competence, Self-Esteem, Cultural, Nursing, Student

\section{Introduction}

Due to the increasing global transnational migration, in 2015, Korean society has 1.74 million foreign residents, accounting for $3.4 \%$ of the total population. And by 2050 , it is expected to exceed $9.2 \%$ [1].

So, multiculturalism is one of the most important issues in Korea at present [2]. This rapid transition of Korean society to multiculturalism is leading to changes in various aspects such as culture, medical care, and welfare. Particularly in the aspect of health care, it is not an exception because a person with diverse cultural and social backgrounds demands health care services [3].

In response to this change it is recognized that nurses are expanding into nursing groups with diverse social and cultural backgrounds. And nurses should also provide them with individual and holistic care. Ultimately, nurses need to have a cultural competence to provide appropriate nursing care by appropriately responding to the various perspectives, values, and behaviors of the health of foreigners with knowledge of cultural traditions, attitudes, and behaviors of multiculturalized care subjects [4][5].

Cultural competence is the ability to understand the influence of culture, to harmonize the culture of the subjects and to provide care [6]. And Based on their knowledge of cultural traditions, attitudes and behaviors of the subjects, they are able to achieve their ability to work

Article history:

Received (July 17, 2016), Review Result (September 01, 2016), Accepted (October 17, 2016) 
effectively in their cultural contexts. Furthermore, it is a dynamic, fluid and continuous process of finding strategies for providing meaningful and useful care [3][7].

Therefore, in order to cultivate the cultural competence of nurses, students who are majoring in nursing should be educated about multiculturalism in the regular curriculum. Also, relevant curriculum should be developed and operated. In order to do so, it is necessary to first identify the influencing factors of cultural competence.

Intercultural communicative competence is the ability to interact with people of different cultural backgrounds in a foreign language [8]. I think it is the ability of the nurse to understand the multicultural subjects properly and to perform the nursing that meets the needs of the target person.

Self-esteem is the judgment of one's ability to perform an action [9]. The belief that a nurse can perform appropriate and individualized nursing for a unique culture of a multicultural subjects [3]. Through self-esteem, nurses will be more active in performing nursing related to multicultural subjects and will achieve higher performance.

Ultimately, if nursing students are educated through regular courses so that they can develop Intercultural communicative competence and self-esteem, the cultural competence required to perform nursing for multicultural subjects will be cultivated.

Therefore, the purpose of this study was to identify the intercultural communicative competence and self-esteem as factors influencing the cultural competence of nursing students. And to provide basic data to reflect the development and operation of nursing curriculum for nurses' core competencies.

\section{Methods}

\subsection{Research subjects}

The number of samples in this study was calculated using $G$ power program [10]. In this study, 158 persons were generated, which met the minimum number of 119 required. The subjects were students enrolled in a nursing department of a university located in D city, and self - enrolled students who agreed to the questionnaire in September, 2016.

\subsection{Research tools}

Measurement tools of intercultural communicative competence was developed by Lee [11] and modified by Lee [12]. The tools was a 5 point scale and consisted of a total of 40 items. The reliability of this tools was Cronbach's $\alpha=.96$.

Measurement tools of self-esteem was developed by Bandura [9] and modified by Ko [13]. The tools was a 5 point scale and consisted of a total of 15 items. The reliability of this tools was Cronbach's $\alpha=.76$.

Measurement tools of cultural competence was developed by Han et al [14]. The tools was a 5 point scale and consisted of a total of 27 items. The reliability of this tools was Cronbach's $\alpha=.91$.

\subsection{Data analysis}

Data were analyzed statistically using SPSS / WIN 18.0 program. The data analysis method was to obtain the mean and standard deviation of the subjects' intercultural communicative competence, self-esteem, cultural competence. The relationship between intercultural communicative competence, self-esteem and cultural competence was analyzed 
using Pearson correlation coefficient. Factors affecting cultural competence were identified as Stepwise multiple regression.

\section{Results}

\subsection{Intercultural communicative competence, self-esteem, multicultural acceptability, cultural competence}

Intercultural communicative competence of subjects was $3.26 \pm .57$ out of 5 . In sub-region, measured skill $3.35 \pm .56$, knowledge $2.88 \pm .75$, attitudes $3.47 \pm .66$, awareness $3.34 \pm .65$.

Self-esteem of subjects was $3.47 \pm .43$ out of 5 . In sub-region, measured inner $3.37 \pm .48$, interperson $3.45 \pm .41$, performance $3.60 \pm .70$.

Cultural competence of subjects was $3.26 \pm .47$ out of 5 . In sub-region, measured awareness $4.21 \pm .52$, knowledge $2.72 \pm .66$, sensitivity $4.10 \pm .58$, skills $3.10 \pm .78$, experience $2.92 \pm .73$ [Table 1].

Table 1. Intercultural communicative competence, self-esteem, and cultural competence $(\mathrm{N}=158)$

\begin{tabular}{|c|c|c|c|}
\hline Variables & Sub Categories & Mean \pm SD & Range \\
\hline \multirow{5}{*}{$\begin{array}{l}\text { Intercultural Communicative } \\
\text { Competence }\end{array}$} & Skills & $3.35 \pm .56$ & \multirow{5}{*}{$1-5$} \\
\hline & Knowledge & $2.88 \pm .75$ & \\
\hline & Attitudes & $3.47 \pm .66$ & \\
\hline & Awareness & $3.34 \pm .65$ & \\
\hline & Total & $3.26 \pm .57$ & \\
\hline \multirow{4}{*}{ Self-Esteem } & Inner & $3.37 \pm .48$ & \multirow{4}{*}{$1-5$} \\
\hline & Interperson & $3.45 \pm .41$ & \\
\hline & Performance & $3.60 \pm .70$ & \\
\hline & Total & $3.47 \pm .43$ & \\
\hline \multirow{6}{*}{ Cultural Competence } & Awareness & $4.21 \pm .52$ & \multirow{6}{*}{$1-5$} \\
\hline & Knowledge & $2.72 \pm .66$ & \\
\hline & Sensitivity & $4.10 \pm .58$ & \\
\hline & Skills & $3.10 \pm .78$ & \\
\hline & Experience & $2.92 \pm .73$ & \\
\hline & Total & $3.26 \pm .47$ & \\
\hline
\end{tabular}

3.2. Correlation between intercultural communicative competence, self-esteem, and cultural competence

Intercultural communicative competence showed a statistically significant positive correlation between self-esteem $(\mathrm{r}=.28, \mathrm{p}<.001)$, and cultural competence $(\mathrm{r}=.55, \mathrm{p}<.001)$.

Self-esteem showed a statistically significant positive correlation between intercultural communicative competence $(\mathrm{r}=.28, p<.001)$, and cultural competence $(\mathrm{r}=.31, p<.001)$. 
Cultural competence showed a statistically significant positive correlation between intercultural communicative competence $(\mathrm{r}=.55, p<.001)$, and self-esteem $(\mathrm{r}=.31, p<.001)$.

Therefore, the greater intercultural communicative competence, the greater self-esteem that cultural capacity increases [Table 2].

Table 2. Correlation between intercultural communicative competence, self esteem, and cultural competence $(\mathrm{N}=158)$

\begin{tabular}{|l|c|c|c|}
\hline \multirow{2}{*}{ Variable } & ICC & SE & CC \\
\cline { 2 - 4 } & \multicolumn{3}{|c|}{$\mathrm{r}(p)$} \\
\hline $\begin{array}{l}\text { Intercultural Communicative } \\
\text { Competence }\end{array}$ & 1 & $.28(<.001)$ & $.55(<.001)$ \\
\hline Self-Esteem & & 1 & $.31(<.001)$ \\
\hline Cultural Competence & & & 1 \\
\hline
\end{tabular}

ICC; Intercultural Communicative Competence. SE; Self-Esteem, CC; Cultural Competence

\subsection{Impact factors on cultural competence}

The effect of intercultural communicative competence and self-esteem on cultural competence of subjects were identified as Stepwise multiple regression.

Intercultural communicative competence showed $30.5 \%$ explanatory power on cultural competence of subjects. And self-esteem showed $30.5 \%$ explanatory power on cultural competence of subjects.

Therefore, intercultural communicative competence and self-esteem on cultural competence of subjects were a factor of cultural competence and showed an explanatory power of $33.3 \%$ [Table 3].

Table 3. Impact factors on Cultural Competence $(\mathrm{N}=158)$

\begin{tabular}{|c|c|c|c|c|c|c|c|}
\hline Variable & $\mathrm{B}$ & $\mathrm{t}$ & $p$ & $\mathrm{R} 2$ & $\begin{array}{c}\text { Adjusted } \\
\mathrm{R} 2\end{array}$ & $\mathrm{~F}$ & $p$ \\
\hline $\begin{array}{c}\text { Intercultural } \\
\text { Communicative } \\
\text { Competence }\end{array}$ & .421 & 7.35 & $<.001$ & \multirow{2}{*}{.333} & .324 & 38.34 & $<.001$ \\
\hline Self-Esteem & .194 & 2.56 & .011 & & & & \\
\hline
\end{tabular}

\section{Conclusion}

Intercultural communicative competence and self-esteem were identified as factors affecting the cultural competence of nursing students. These results will be used to develop and operate curriculum to cultivate cultural competence of nursing students.

\section{References}

[1] Ministry of Public Administration and Security. Statistics on Foreign Residents by Local Governments, Retrieved August 5, 2015, from http://www.mogaha.go.kr/frt/bbs/type001/commomSelectBoardArticle.do? bbsId=BBSMSTR-00000000014\&nttId=46327, (2015)

[2] Y. K. Hyun, "The influence of multicultural contact experiences on multicultural acceptability of university students," M.S. thesis, Dongguk University, Seoul, (2016)

[3] M. K. Cho and H. Y. Jang, "Factors influencing cultural competency among nursing students," Journal of the Korean Data Analysis Society, vol.17, no.5, pp.2795-2808, (2015) 
[4] M. S. Ko, E. H. Choi, and K. O. Choi, "A study on the relationship of cultural competence, Self-Efficacy and job stress in nurses caring for hospitalized foreign patients," Journal of Korean Clinical Nursing Research, vol.22, no.1, pp.68-77, (2016)

[5] M. R. Jeffreys and E. Dogan, "Evaluating the influence of cultural competence education on students 'transcultural Self-Efficacy perceptions," Journal of Transcultural Nursing, vol.23, no.2, pp.188-197, (2012) DOI: $10.1177 / 1043659611423836$

[6] J. Campinha-Bacote, "The process of cultural competence in the delivery of healthcare services: A model of care," Journal of Transcultural Nursing, vol.13, no.3, pp.181-184, (2002) DOI: $10.1177 / 10459602013003003$

[7] J. Campinha-Bacote, "Becoming culturally competent in ethnic psychopharmacology," Journal of Psychosocial Nursing and Mental Health Service, vol.45, no.9, pp.27-33, (2007) DOI: 10.1111/j.13652850.2007.01110.x

[8] M. Byram, "Teaching and assessing intercultural communicative competence," Clevedon, UK, Multilingual Matters, (1997)

[9] A. Bandura, "Self-Efficacy: The exercise of control," New York, NY: Freeman, (1977)

[10] F. Faul, E. Erdfelder, A. G. Lang, and A. Buchner, "G*Power 3: A flexible statistical power analysis power analysis program for the social, behavior, and biomedical sciences," Behavior Research Methods, vol.39, no.2, pp.175-191, (2011) DOI: 10.3758/BF03193146

[11] D. W. Lee, "A comparative study of intercultural communicative competence of Korean students as sojourners and American universities," Journal of Communication Studies, vol.19, no.4, pp.65-84, (2011)

[12] E. M. Lee, "Variables affecting the intercultural communication skills of nursing students," Unpublished master's thesis, Daegu Catholic University, Daegu, (2013)

[13] E. J. Ko, "Improvement of underachiever's confidence and Self-esteem using music therapy program," Unpublished master's thesis, Korea National University, Chungbuk, (2004)

[14] S.Y. Han and H. I. Chung, "Development of a culteral competence scale for nursing students," Journal of Korean Academy Nursing, vol.45, no.5, pp.684-693, (2015) 
Intercultural Communicative Competence, Self-Esteem Cultural Competence of Nursing Students

This page is empty by intention. 